\title{
Readmission rates following esophageal cancer resection are similar at regionalized and non-regionalized centers: A population-based cohort study
}

Vaibhav Gupta, MD, ${ }^{\mathrm{a}, \mathrm{b}}$ Lev Bubis, MD, ${ }^{\mathrm{a}, \mathrm{b}}$ Biniam Kidane, MD, MSc, ${ }^{\mathrm{c}}$ Alyson L. Mahar, $\mathrm{PhD},{ }^{\mathrm{d}}$ Jolie Ringash, MD, MSc, ${ }^{\text {,e }}$ Rinku Sutradhar, PhD, ${ }^{\text {, f }}$ Gail E. Darling, MD, ${ }^{\mathrm{a}, \mathrm{b}, \mathrm{g}}$ and Natalie G. Coburn, MD, MPH ${ }^{\mathrm{a}, \mathrm{b}, \mathrm{h}}$

\section{ABSTRACT}

Objective: Readmission following esophagectomy affects the patient experience, has important economic implications, and can be tied to hospital reimbursement. Ontario has regionalized thoracic centers; regionalized surgery may lower the readmission rate. We investigated whether surgery at regionalized thoracic centers is associated with reduced readmission following esophageal cancer resection.

Methods: A retrospective, population-based cohort study (2002-2014) was conducted in Ontario, Canada (population 13.6 million). Adults with resected esophageal cancer were identified through the Ontario Cancer Registry. Multivariable regression was used to estimate the effect of surgery at a regionalized thoracic surgery center on readmission to any Ontario hospital within 90 days following discharge.

Results: Of 3670 patients, $27.9 \%$ were readmitted within 90 days of discharge $(\mathrm{n}=1022)$. Median hospital length of stay was 12 days (interquartile range 920). The readmission rate at thoracic centers was similar to other hospitals (28.1\% vs $27.1 \%, P=.57)$. The readmission rate did not change during the 13 -year study period. Case-mix adjusted readmission rates varied from 17.6\% to $35.2 \%$ even across thoracic centers and were not related to hospital volume or perioperative mortality. After adjusting for confounders, we found that surgery at a thoracic center was not significantly associated with readmission (odds ratio, $1.10 ; 95 \%$ confidence interval, $0.95-1.27, P=.22$ ).

Conclusions: Surgery at a designated thoracic surgery center did not reduce the risk of 90-day readmission following esophageal cancer resection, and readmission rates varied significantly even across thoracic centers. Our results suggest that despite universal, regionalized esophageal cancer care, there appears to be a minimum readmission threshold following esophagectomy that may be clinically necessary. (J Thorac Cardiovasc Surg 2019;158:934-42)

\begin{tabular}{|c|c|c|}
\hline \multicolumn{3}{|c|}{$\begin{array}{l}\text { 90-Day Readmission Following Esophagectomy at } \\
\text { Regionalized and Non-Regionalized Centres }\end{array}$} \\
\hline \multicolumn{3}{|c|}{ 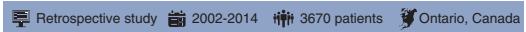 } \\
\hline $\begin{array}{l}\text { No change in } \\
\text { readmission rate } \\
\text { over } 13 \text { years }\end{array}$ & $\begin{array}{l}\text { Similar readmission } \\
\text { rate at both } \\
\text { type of centres }\end{array}$ & $\begin{array}{l}\text { Varying readmission } \\
\text { rate even at } \\
\text { regionalized centres }\end{array}$ \\
\hline 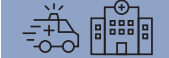 & 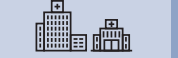 & ㅁำ \\
\hline $28 \%$ readmitted & $28 \%$ vs $27 \%$ & $18 \%$ to $35 \%$ \\
\hline \multicolumn{3}{|c|}{$\begin{array}{l}\text { There appears to be a minimum readmission threshold } \\
\text { following esophagectomy \& may be clinically necessary }\end{array}$} \\
\hline \multicolumn{3}{|c|}{$\begin{array}{l}\text { Graphical abstract summarizing key study character- } \\
\text { istics and results. }\end{array}$} \\
\hline \multicolumn{3}{|c|}{ Central Message } \\
\hline \multicolumn{3}{|c|}{$\begin{array}{l}\text { Despite universal, regionalized, high-volume } \\
\text { esophageal cancer care in Ontario, there ap- } \\
\text { pears to be a minimum readmission threshold } \\
\text { following esophagectomy that may be clini- } \\
\text { cally necessary. }\end{array}$} \\
\hline
\end{tabular}

\section{Perspective}

Readmission following esophagectomy affects the patient experience, has important economic implications, and can be tied to hospital reimbursement. Despite universal health insurance and rigorous hospital standards for regionalized surgery in Ontario, the readmission rate was $28 \%$ at thoracic centers. For such morbid procedures, there may be a minimum clinically necessary readmission rate.

See Commentary on page 943.
From the ${ }^{\mathrm{a}}$ Department of Surgery, ${ }^{\mathrm{b}}$ Institute of Health Policy, Management, and Evaluation, and ${ }^{\mathrm{e}}$ Department of Radiation Oncology, University of Toronto, Toronto; ${ }^{\mathrm{c}}$ Department of Surgery and ${ }^{\mathrm{d}}$ Manitoba Centre for Health Policy, University of

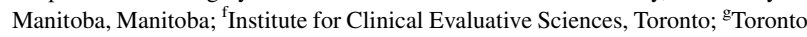

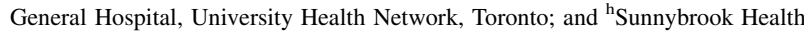
Sciences Centre, Toronto, Ontario, Canada.

This research was supported by the Sherif and MaryLou Hanna Chair in Surgical Oncology through operating funds and salary support for Drs Gupta and Coburn. This study was supported by the Institute for Clinical Evaluative Sciences (ICES), which is funded by an annual grant from the Ontario Ministry of Health and Long-Term Care (MOHLTC). Parts of this material are based on data and/or information compiled and provided by the Canadian Institute for Health Informa- tion (CIHI) and by Cancer Care Ontario. The analyses, opinions, results, and conclusions reported in this paper are those of the authors and are independent from ICES, MOHLTC, CIHI, and Cancer Care Ontario. No endorsement by any of these organizations is intended or should be inferred.

Received for publication Nov 8, 2018; revisions received March 28, 2019; accepted for publication April 16, 2019; available ahead of print June 5, 2019.

Address for reprints: Vaibhav Gupta, MD, Sunnybrook Health Sciences Centre, K3W-15, 2075 Bayview Ave, Toronto, Ontario M4N 3M5 Canada (E-mail: Vaibhav.Gupta@mail.utoronto.ca). $0022-5223 / \$ 36.00$

Copyright (C) 2019 by The American Association for Thoracic Surgery https://doi.org/10.1016/j.jtcvs.2019.04.061 

Abbreviations and Acronyms
$\mathrm{CI}=$ confidence interval
$\mathrm{EC}=$ esophageal cancer
$\mathrm{ICU}=$ intensive care unit
LHIN $=$ Local Health Integration Network
OCR $=$ Ontario Cancer Registry
$\mathrm{OR}=$ odds ratio

\section{Scanning this QR code will \\ take you to the article title page to access supplementary information.}

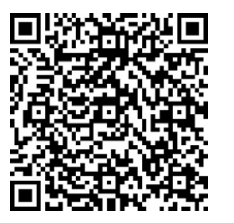

Esophageal cancer (EC) carries a significant treatment burden for patients and the health care system. ${ }^{1}$ Following curative-intent resection, patients may experience repeat hospital visits for postoperative complications as they go through the intensive process of recovery and adaptation to eating without an esophagus. The readmission rate following esophagectomy is as high as $20 \%$ by 30 days and $50 \%$ by 1 year. ${ }^{2,3}$ This high rate of postoperative health care use has important economic implications for health care systems. Illustratively, in the province of Ontario, Canada, EC has the greatest per-patient treatment cost among all cancers. ${ }^{4}$ Hospital admissions for surgery and readmissions for postoperative complications account for the majority of the cost of curative treatments. ${ }^{4}$ From a health policy perspective, readmission rates are now used as a quality indicator for health systems; for example, they are tied to reimbursement through the Hospital Readmissions Reduction Program in the United States, with reduced payments to hospitals with excess readmissions for conditions including acute myocardial infarction, heart failure, and pneumonia.

Regionalization of surgery to subspecialized hospitals and surgeons has a well-established relationship with improved postoperative outcomes. ${ }^{6,7}$ Multiple factors may contribute to this relationship, including greater volumes, multidisciplinary management, and improved resources such as disease-specific postoperative pathways, specialized nursing units, and availability of advanced interventional radiology, gastroenterology, and anesthesia support. In the early 2000s, most thoracic surgery was performed in highvolume centers in Ontario. However, regionalization was formalized from 2005 to 2010 , with designated centers established to improve outcomes for several high-risk and resource-intensive patient populations. Regionalization standards were set by Cancer Care Ontario, a provincial agency mandated by the Government of Ontario to provide leadership in cancer care. ${ }^{8}$ Although postoperative mortality is reduced with regionalized or high-volume surgery, ${ }^{6,9-13}$ the effect of surgery at a regionalized center on hospital readmissions is not well explored in the literature. Furthermore, as not all jurisdictions in North America and Europe have systematically regionalized thoracic or upper gastrointestinal surgery, evidence from the Ontario experience may help clinicians and policy-makers in other regions decide whether to implement regionalization. The objective of this study is to evaluate whether surgery at regionalized thoracic centers is associated with the readmission rate following esophageal cancer resection in Ontario.

\section{METHODS}

\section{Study Design and Setting}

We performed a retrospective, population-based cohort study of adults diagnosed with EC in Ontario, Canada (population 13.6 million). Patients were identified in the Ontario Cancer Registry (OCR). Maintained by Cancer Care Ontario, the OCR is a provincial registry of incident cancer diagnoses and captures $96 \%$ of cancer diagnoses in Ontario. ${ }^{14,15}$

Ethics approval for this study was obtained from the Sunnybrook Health Sciences Centre Research Ethics Board, and we adhered to the data confidentiality and privacy policies of the Institute for Clinical Evaluative Sciences.

\section{Study Participants}

All patients with resected esophageal and gastroesophageal junction cancer diagnosed between 2002 and 2014 were identified using relevant topography, histology, and surgical codes (Table E1, Appendix E1). Patients were excluded if they were younger than 18 years of age, not eligible for government health insurance, or had a cancer type other than adenocarcinoma or squamous cell carcinoma.

\section{Data Sources}

Population-based data for this cohort were linked from the following sources (Table E2): OCR, Ontario Health Insurance Plan Database, Canadian Institute for Health Information Discharge Abstract Database, Registered Persons Database, and the 2006 Canadian Census. These datasets were linked using unique encoded identifiers and analyzed at the Institute for Clinical Evaluative Sciences.

\section{Exposure and Outcome Definitions}

The exposure of interest for this study was receipt of surgery at a Cancer Care Ontario-designated thoracic surgery center (regionalized center) or other, non-thoracic center. This was defined as a categorical variable (yes/no). The primary outcome was readmission within 90 days following discharge from the index hospital stay. Readmission to any hospital in Ontario was captured. Readmission in Ontario is defined as any patient who requires admission to the hospital from home, outpatient setting, or the emergency department for further workup or treatment and includes short stays that may be classified as "observation" and not readmission in the United States. Patients who died in the hospital before discharge were not included in the readmission analysis. Perioperative mortality (in-hospital and 90-day postdischarge mortality) across thoracic centers was included as a secondary outcome (categorical yes/no variable) to assess whether differences in this outcome may have influenced the primary outcome. Follow-up data were current to November 2016, with complete 90-day follow-up from the date of discharge for all included patients. 


\section{Covariates}

The following known and available covariates were studied: age, sex, comorbidity, socioeconomic status, histology, receipt of neoadjuvant chemotherapy or radiotherapy, hospital length of stay, intensive care unit (ICU, ie, high-dependency, step-down, or intensive care unit) length of stay, major postoperative complications, discharge disposition, region of residence, and year of treatment. Age at diagnosis was used as a categorical variable based on operative risk groups: 18 to 60 years (standard risk), 61 to 70 years (moderately high risk), and $\geq 71$ years (high risk). Comorbidity was measured by the sum of patients' Aggregated Diagnosis Groups using the Johns Hopkins Adjusted Clinical Groups methodology, and was categorized as low (0-4), moderate (5-9), and high $(\geq 10)$ comorbidity. ${ }^{16}$ The median neighborhood income based on patients' postal code was used as a surrogate for socioeconomic status and was divided into quintiles based on Canadian census data. ${ }^{17,18}$ Histology was categorized as adenocarcinoma or squamous cell carcinoma (Table E1). Receipt of neoadjuvant chemotherapy and radiotherapy was defined as presence of at least 2 treatment visits within 180 days before surgery. Hospital length of stay indicated the total number of days the patient was admitted to hospital following surgery; interhospital transfers after surgery were considered as part of the index surgical admission. Length of stay was categorized based on the 25th and 75th percentiles into short stay ( $\leq 10$ days), typical stay (10-20 days), and prolonged stay ( $\geq 21$ days). ICU length of stay was categorized based on clinical judgment into typical stay (0-2 days), limited stay (3-9 days), and prolonged stay ( $\geq 10$ days). Major postoperative complications were considered present if the patient experienced cerebrovascular accident, myocardial infarction, acute kidney injury, respiratory failure, pneumonia, airway compromise, pulmonary embolism, deep-vein thrombosis, cardiac arrest, shock, sepsis, or procedure-related complications such as bleeding. Discharge disposition following index surgical admission was a 3-level categorical variable including discharge home without community support, discharge home with support (such as home care nursing), or transfer to another facility (such as rehabilitation or continuing care). Region of residence was operationalized as the Local Health Integration Network (LHIN), where the patient lived to adjust for differences in treatment delivery across the province. LHIN is a geographic unit defined by the Province as responsible to deliver health care to the population of that region. Finally, year of treatment was included to adjust for temporal trends in patient management (categorized into 2 groups, 20022008 or 2009-2014).

\section{Statistical Methods}

Descriptive statistics were used to describe baseline demographics. Reasons for the first readmission within 90 days following discharge were categorized by system. Continuous data are presented with means and standard deviations and were analyzed using independent sample $t$ tests if normally distributed; non-normally distributed data are presented with medians and interquartile ranges and were analyzed using the Wilcoxon rank sum test. Categorical data are presented as frequencies and proportions; comparisons were performed using the $\chi^{2}$ test. There was minimal missing data $(<1 \%)$.

A multivariable marginal model (generalized estimating equation) was used to estimate the independent association between surgery at a thoracic center and 90-day readmission, after adjusting for confounders and accounting for clustering at the hospital level with a compound symmetry covariance structure. Clinically informed confounders were determined a priori and adjusted in the multivariable model: age, sex, residence status, socioeconomic status, comorbidity, and era of treatment. Hospital length of stay and discharge disposition were considered mediators and not included in the model. A $P$ value $<.05$ was considered statistically significant. The model was evaluated by ensuring a significant likelihood-ratio Omnibus test. Absence of multicollinearity between variables was assessed using the variance inflation factor. Model fit and overspecification were assessed by ensuring model convergence. Influential outliers were evaluated graphically using Pearson/Deviance residuals.

The following sensitivity analyses were performed to test our assumptions: (1) we assessed the relationship between ICU length of stay and readmission as a continuous rather than categorical variable in the model, (2) we included individual year of surgery in the model (instead of 2 categories), (3) we tested the hypothesis that hospital length of stay and discharge disposition are mediators by running multivariable models with and without them included, and (4) we included major postoperative complications in the multivariable model to assess their association with readmission and effect on the relationship between surgery at a thoracic center and readmission.

All tests were 2-tailed and were performed using the SAS software application (version 9.2: SAS Institute, Cary, NC).

\section{RESULTS \\ Baseline Characteristics}

Of 3670 patients included in the study, $27.8 \%$ were readmitted within 90 days of hospital discharge $(\mathrm{n}=1022)$. Average age was 64 years, $23 \%$ were female, $85 \%$ had adenocarcinoma, and median hospital length of stay was 12 days (interquartile range 9-20, Table 1). Patients treated at thoracic centers were less likely to be female, slightly less comorbid, had shorter overall hospital stay, longer ICU stay, and were more frequently discharged home with community supports compared with patients treated at nonthoracic centers (Table 1). Readmitted patients were more likely to be female, have greater baseline comorbidity burden, and longer length of hospital stay at the index admission for esophagectomy (Table 2). The overall readmission rate did not change during the 13-year study period (Figure 1). Reasons for the first readmission within 90 days following discharge are shown in Table 3.

\section{Effect of Thoracic Surgery Centers}

Most patients (76\%) had surgery at a designated thoracic center; this increased from $63 \%$ in 2002 to $94 \%$ in 2014 . Case-mix adjusted readmission rates varied even across designated thoracic centers, ranging from $17.6 \%$ to $35.2 \%$, and were not related to hospital case volume or perioperative mortality (Figure 2). Complications at thoracic and non-thoracic centers are shown in Table E3. The readmission rate at thoracic centers was similar to other hospitals $(28.1 \%$ vs $27.1 \%, P=.57)$. However, patients undergoing surgery at thoracic centers had lower perioperative mortality $(9.4 \%$ vs $13.9 \%, P<.001)$.

\section{Factors Associated With Readmission}

Results from the multivariable marginal model identifying factors independently associated with 90-day readmission are shown in Table 4. After adjusting for covariates of interest, we found that surgery at a thoracic center was not significantly associated with 90-day readmission (odds ratio [OR], 1.10; 95\% confidence interval $[\mathrm{CI}], 0.95-1.27, P=.22)$. However, female sex (OR, 1.25; 
TABLE 1. Baseline demographics of the cohort

\begin{tabular}{|c|c|c|c|c|}
\hline Characteristic & $\begin{array}{l}\text { All patients } \\
(\mathbf{n}=\mathbf{3 6 7 0})\end{array}$ & $\begin{array}{l}\text { Treated at thoracic center } \\
\quad(\mathrm{n}=\mathbf{2 7 7 7}, \mathbf{7 5 . 7} \%)\end{array}$ & $\begin{array}{l}\text { Treated at non-thoracic center } \\
\qquad(\mathrm{n}=\mathbf{8 9 3}, \mathbf{2 4 . 3} \%)\end{array}$ & $P$ value \\
\hline Age, y, mean (standard deviation) & $63.6(11.1)$ & $63.4(10.9)$ & $64.0(11.9)$ & .17 \\
\hline Female sex & $853(23.2 \%)$ & $591(21.3 \%)$ & $262(29.3 \%)$ & $<.001$ \\
\hline Urban residence & $3080(84.1 \%)$ & $2250(81.0 \%)$ & $830(92.9 \%)$ & $<.001$ \\
\hline $\begin{array}{l}\text { Income quintile } \\
\text { (Lowest) } 1 \\
2 \\
3 \\
4 \\
\text { (Highest) } 5\end{array}$ & $\begin{array}{l}712(19.5 \%) \\
715(19.6 \%) \\
788(21.6 \%) \\
739(20.3 \%) \\
695(19.1 \%)\end{array}$ & $\begin{array}{l}547(19.7 \%) \\
534(19.2 \%) \\
592(21.3 \%) \\
551(19.8 \%) \\
533(19.2 \%)\end{array}$ & $\begin{array}{l}165(18.5 \%) \\
181(20.3 \%) \\
196(21.9 \%) \\
188(21.1 \%) \\
162(18.1 \%)\end{array}$ & .28 \\
\hline Adenocarcinoma & $3106(84.6 \%)$ & $2333(84.0 \%)$ & $773(86.6 \%)$ & .07 \\
\hline $\begin{array}{l}\text { Comorbidity } \\
\text { Low } \\
\text { Moderate } \\
\text { High }\end{array}$ & $\begin{array}{r}788(21.5 \%) \\
2019(55.0 \%) \\
863(23.5 \%)\end{array}$ & $\begin{array}{r}624(22.5 \%) \\
1516(54.6 \%) \\
637(22.9 \%)\end{array}$ & $\begin{array}{l}164(18.4 \%) \\
503(56.3 \%) \\
226(25.3 \%)\end{array}$ & .03 \\
\hline Neoadjuvant chemotherapy & $1104(30.1 \%)$ & $989(35.6 \%)$ & $115(12.9 \%)$ & $<.001$ \\
\hline Neoadjuvant radiotherapy & $798(21.7 \%)$ & $754(27.2 \%)$ & $44(4.9 \%)$ & $<.001$ \\
\hline Major postoperative complications & $985(26.8 \%)$ & $756(27.2 \%)$ & $229(25.6 \%)$ & .35 \\
\hline $\begin{array}{l}\text { Hospital length of stay, d, median (IQR) } \\
\quad \leq 10 \\
11-20 \\
21+\end{array}$ & $\begin{array}{r}12(9-20) \\
1321(36.0 \%) \\
1433(39.1 \%) \\
916(25.0 \%)\end{array}$ & $\begin{array}{r}12(9-19) \\
1086(39.1 \%) \\
1049(37.8 \%) \\
642(23.1 \%)\end{array}$ & $\begin{array}{c}14(10-24) \\
235(26.3 \%) \\
384(43.0 \%) \\
274(30.7 \%)\end{array}$ & $<.001$ \\
\hline $\begin{array}{l}\text { ICU length of stay, d, median (IQR) } \\
0-2 \\
3-7 \\
\geq 8\end{array}$ & $\begin{array}{c}3(0-6) \\
1692(46.1 \%) \\
1254(34.2 \%) \\
724(19.7 \%)\end{array}$ & $\begin{array}{c}3(0-6) \\
1243(44.8 \%) \\
992(35.7 \%) \\
542(19.5 \%)\end{array}$ & $\begin{array}{c}2(0-6) \\
449(50.3 \%) \\
262(29.3 \%) \\
182(20.4 \%)\end{array}$ & .002 \\
\hline $\begin{array}{l}\text { Discharge disposition } \\
\text { Home without supports } \\
\text { Home with supports } \\
\text { Transfer to facility }\end{array}$ & $\begin{array}{c}1354(36.9 \%) \\
2105(57.4 \%) \\
211(5.8 \%)\end{array}$ & $\begin{array}{r}859(30.9 \%) \\
1775(63.9 \%) \\
143(5.1 \%)\end{array}$ & $\begin{array}{c}495(55.4 \%) \\
330(37.0 \%) \\
68(7.6 \%)\end{array}$ & $<.001$ \\
\hline $\begin{array}{l}\text { Era of treatment } \\
2002-2008 \\
2009-2014\end{array}$ & $\begin{array}{l}1909(52.0 \%) \\
1761(48.0 \%)\end{array}$ & $\begin{array}{l}1302(46.9 \%) \\
1475(53.1 \%)\end{array}$ & $\begin{array}{l}607(68.0 \%) \\
286(32.0 \%)\end{array}$ & $<.001$ \\
\hline
\end{tabular}

$I Q R$, Interquartile range; $I C U$, intensive care unit.

95\% CI, 1.12-1.39, $P<.001)$ and comorbidity burden (moderate: OR, 1.51; 95\% CI, 1.19-1.91, $P<.001$; high: OR, 2.28; 95\% CI, 1.43-3.63, $P<.001)$ were risk factors for 90-day readmission. Interestingly, age, income, rural residence, LHIN of residence, and years were not associated with risk of readmission.

\section{Sensitivity Analyses}

The results were unchanged by examining ICU length of stay as a continuous variable or including individual year of surgery in the multivariable model. Multivariable models including hospital length of stay and discharge disposition decreased the association between surgery at a thoracic center and readmission, suggesting they are mediators. Major postoperative complications were associated with increased risk of readmission (OR, 1.50; 95\% CI, 1.27-1.77, $P<.001$ ) and did not change the nonsignificant relationship between surgery at a thoracic center and readmission.

\section{DISCUSSION}

In this large population-based study, we found that surgery at a designated thoracic surgery center was not associated with reduced risk of 90-day readmission compared with other hospitals following regionalization of thoracic surgery in Ontario, Canada (Central Picture). The majority of previous studies assessing the volume-outcome relationship after esophagectomy have focused on perioperative mortality, or short-term outcomes such as length of stay and surgical complications. ${ }^{6,9,11-13}$ A 2012 meta-analysis that pooled estimates from 9 studies and more than 27,000 patients found reduced in-hospital $(2.82 \%$ vs $8.48 \%)$ and 30 -day mortality $(0.73 \%$ vs $2.09 \%)$ at greater-volume 
TABLE 2. Comparing patient characteristics by 90-day readmission status (primary outcome)

\begin{tabular}{|c|c|c|c|}
\hline Characteristic & $\begin{array}{c}\text { Not readmitted } \\
(\mathrm{n}=\mathbf{2 6 4 8}, \mathbf{7 2 . 2} \%)\end{array}$ & $\begin{array}{c}\text { Readmitted } \\
(\mathrm{n}=\mathbf{1 0 2 2}, \mathbf{2 7 . 8} \%)\end{array}$ & $P$ value \\
\hline Age, y, mean (standard deviation) & $63.7(11.1)$ & $63.4(11.4)$ & .51 \\
\hline Female sex, $(\%)$ & $584(22.1)$ & $269(26.3)$ & .006 \\
\hline Urban residence, $(\%)$ & $2227(84.1)$ & $853(83.5)$ & .82 \\
\hline $\begin{array}{l}\text { Income quintile, (\%) } \\
\text { (Lowest) } 1 \\
2 \\
3 \\
4 \\
\text { (Highest) } 5\end{array}$ & $\begin{array}{l}508(19.2) \\
524(19.8) \\
555(21.0) \\
524(19.8) \\
521(19.7)\end{array}$ & $\begin{array}{l}204(20.0) \\
191(18.7) \\
233(22.8) \\
215(21.0) \\
174(17.0)\end{array}$ & .38 \\
\hline Adenocarcinoma (vs SCC), (\%) & $2244(84.7)$ & $862(84.3)$ & .76 \\
\hline $\begin{array}{l}\text { Comorbidity, }(\%) \\
\text { Low } \\
\text { Moderate } \\
\text { High }\end{array}$ & $\begin{array}{r}609(23.0) \\
1438(54.3) \\
601(22.7)\end{array}$ & $\begin{array}{l}179(17.5) \\
581(56.8) \\
262(25.6)\end{array}$ & $<.001$ \\
\hline Neoadjuvant chemotherapy, $(\%)$ & $807(30.5)$ & $297(29.1)$ & .40 \\
\hline Neoadjuvant radiotherapy, $(\%)$ & $580(21.9)$ & $218(21.3)$ & .71 \\
\hline Major postoperative complications, $(\%)$ & $653(24.7)$ & $332(32.5)$ & $<.001$ \\
\hline $\begin{array}{l}\text { Hospital length of stay, } \mathrm{d},(\%) \\
\quad \leq 10 \\
11-20 \\
21+\end{array}$ & $\begin{array}{r}1002(37.8) \\
1046(39.5) \\
600(22.7)\end{array}$ & $\begin{array}{l}319(31.2) \\
387(37.9) \\
316(30.9)\end{array}$ & $<.001$ \\
\hline $\begin{array}{l}\text { ICU length of stay, } d,(\%) \\
0-2 \\
3-7 \\
\geq 8\end{array}$ & $\begin{array}{r}1234(46.6) \\
916(34.6) \\
498(18.8)\end{array}$ & $\begin{array}{l}458(44.8) \\
338(33.1) \\
226(22.1)\end{array}$ & .08 \\
\hline $\begin{array}{l}\text { Discharge disposition, }(\%) \\
\text { Home without supports } \\
\text { Home with supports } \\
\text { Transfer to facility }\end{array}$ & $\begin{array}{c}1001(37.8) \\
1493(56.4) \\
154(5.8)\end{array}$ & $\begin{array}{l}353(34.5) \\
612(59.9) \\
57(5.6)\end{array}$ & .15 \\
\hline Surgery at thoracic center, $(\%)$ & $1997(75.4)$ & $780(76.3)$ & .57 \\
\hline $\begin{array}{l}\text { Era of treatment, }(\%) \\
\text { 2002-2008 } \\
2009-2014\end{array}$ & $\begin{array}{l}1373(51.9) \\
1275(48.1)\end{array}$ & $\begin{array}{l}536(52.4) \\
486(47.6)\end{array}$ & .75 \\
\hline
\end{tabular}

Bold indicates statistically significant values. $S C C$, Squamous cell carcinoma; $I C U$, intensive care unit.

centers. ${ }^{19}$ These studies have not looked at the impact on readmissions, which is an important quality metric from the patient and health system perspective.

Unlike length of stay, complications, and perioperative mortality, which are outcomes focused at the patient and hospital level, readmission is also influenced by the local health system. Discharge planning, community supports, patient follow-up, delayed surgical complications, and outpatient access to the health care team all play a role in subsequent hospital readmissions. In Ontario, standards for "level 1" thoracic center designation include having 3 fellowship-trained thoracic surgeons on staff, and performing at least 20 esophagectomies and 150 lung resections per year at the center. ${ }^{8}$ The hospital must have availability of an intensive care, as well as 24/7 access to the operating room, interventional radiology, diagnostic imaging, specialized nursing, laboratory, and pathology services. Furthermore, the center must have commitment to multidisciplinary care through all phases of care, including affiliation with a regional cancer center. The guidelines do not include recommendations on outpatient care and support services. Despite these rigorous hospital standards to provide highvolume and high-quality esophageal cancer care, the readmission rate was $28 \%$ at thoracic centers. Similar results were found in an analysis of lung cancer resection outcomes during regionalization in Ontario. ${ }^{20} \mathrm{~A}$ Medicare analysis of 


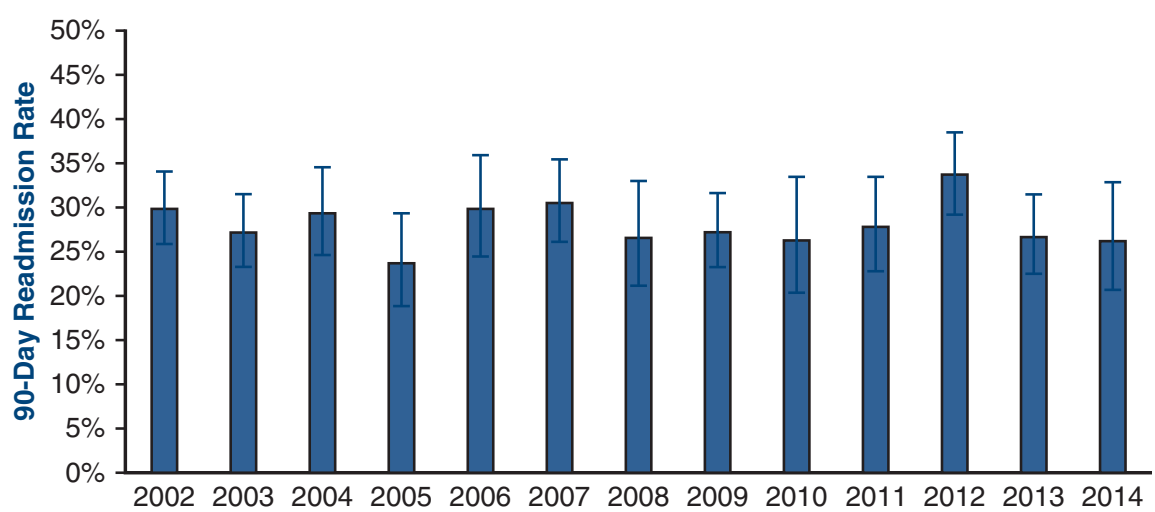

FIGURE 1. Ninety-day readmission rates following esophagectomy in Ontario by year from 2002 to 2014, adjusted for age, sex, and comorbidity. Error bars represent the $95 \%$ confidence interval. Readmission rates remained relatively stable over the 13 -year study period.

increasing hospital volume for 14 cardiovascular and cancer procedures that included esophagectomy also did not find an association with 30-day readmission. ${ }^{21}$

One hypothesis is that for such a highly-morbid procedure, there is a minimum readmission rate that patients and physicians must accept as part of the risk of surgery. Indeed, there are data to support this possibility. For example, despite advances in nutrition support, perioperative care, and the introduction of minimally invasive surgical techniques, reported readmission rates after esophagectomy have remain relatively constant over the last decade. ${ }^{22-26}$ Importantly, if a minimal amount of readmissions occur with a major operation such as esophagectomy, decisions to financially penalize the institution may not be warranted, as some readmissions may be unavoidable.

Ontario has a universal, single-payer health system. Theoretically, this reduces care fragmentation since interfacility transfers, outpatient care, and specialist follow-up can be organized as necessary for patients without worry for insurance systems and reimbursement. Furthermore, there are

TABLE 3. Categories of reasons for the first readmission within 90 days following esophagectomy discharge

\begin{tabular}{lc}
\hline Reason for readmission & Number $(\%)$ \\
\hline Gastrointestinal & $305(27.3)$ \\
Respiratory & $187(16.8)$ \\
Cardiovascular & $110(9.9)$ \\
Cancer-related & $103(9.2)$ \\
\hline Postoperative complication & $88(7.9)$ \\
Infection & $52(4.7)$ \\
Endocrine & $44(3.9)$ \\
Genitourinary & $34(3.1)$ \\
\hline Psychiatric or neurologic & $24(2.2)$ \\
Pain & $24(2.2)$ \\
Hematologic & $22(2.0)$ \\
Other & $141(12.6)$ \\
\hline
\end{tabular}

no financial penalties for hospital readmissions, such as in the US Hospital Readmissions Reduction Program, allowing the discharge decision to be focused on clinical criteria without fear of potential readmission costs for the discharging hospital. Both characteristics should have allowed Ontario to realize the benefits of regionalization on readmission after esophagectomy. Finding no impact on the readmission rate with regionalization speaks strongly to the idea of a minimum expected and accepted readmission rate for high-risk procedures, described by others as a "readmission floor." ${ }^{27,28}$ Tellingly, the 3 greatestvolume thoracic centers in Ontario all had a readmission rate greater than $25 \%$. An analysis of the American College of Surgeons National Quality Improvement Program in 2018 showed that surgical complications drive readmission following esophagectomy. ${ }^{2}$ In this setting, readmission and rescue is a clinically necessary priority to ensure a good outcome. Financial penalty for all readmissions, without appreciating a certain percentage of unpreventable readmissions for surgical patients, may place unreasonable expectations of a perfect outcome on patients, surgeons, and hospitals in jurisdictions where such penalties are imposed. Although there is currently no health policy that specifically monitors or penalizes readmission after esophagectomy, data from our study will be necessary for policymakers to consider before such measures are proposed.

Importantly, even among these specialized centers, the readmission rate varied from $17.6 \%$ to $35.2 \%$. As this variation does not appear to be related to volume, next steps should include examination of the processes of care and pathways that are used at the low-readmission hospitals, to create similar programs at the greater readmission hospitals. Efforts to improve the readmission rate will also need to focus outside hospitals, and include local health system changes, to help patients with preventable readmissions be treated out of hospital. Of note, readmission rates in our study may appear "high" due to complete capture through administrative data in Ontario. Our data captured 


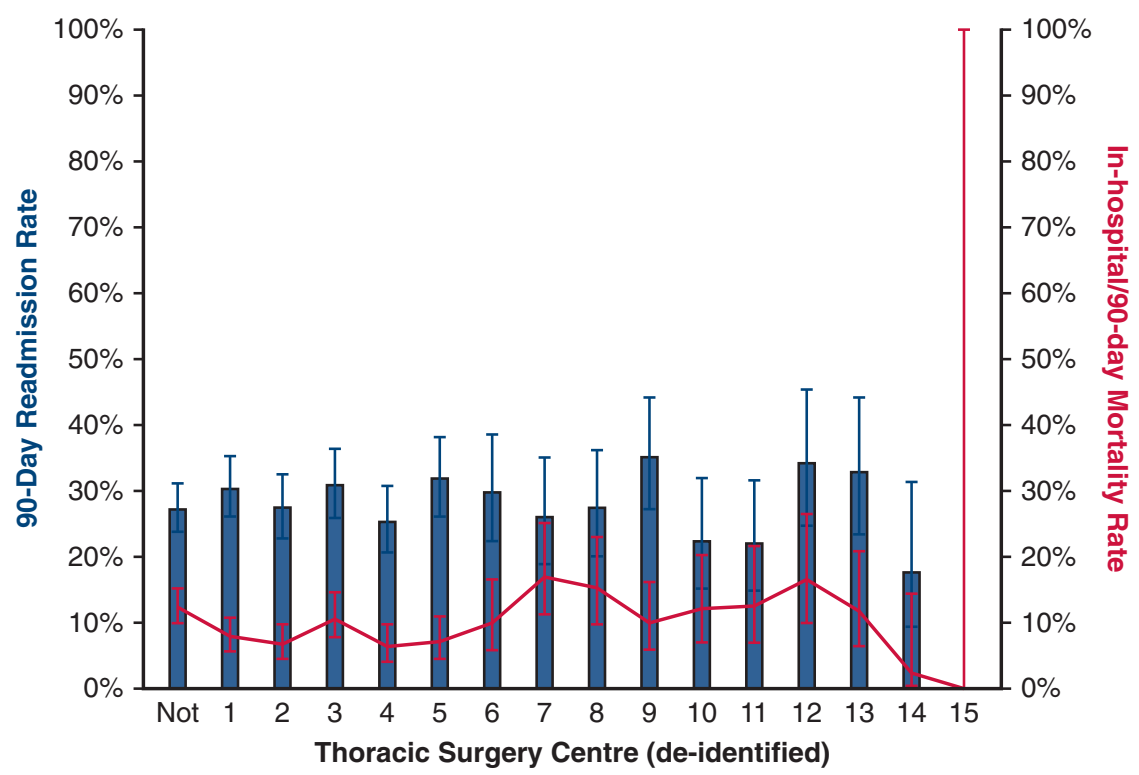

FIGURE 2. Ninety-day readmission and in-hospital/90-day mortality rates at non-thoracic centers, compared with thoracic centers, following esophagectomy in Ontario. Rates are adjusted for case mix (age, sex, comorbidity, rural residence, income quintile, and year), and error bars represent the $95 \%$ confidence interval. Thoracic centers are ordered from highest volume (1) to lowest volume (15). Readmission rates varied across thoracic centers, and were not related to hospital volume or in-hospital/90-day mortality.

all readmissions to any hospital in the province, including to index and non-index hospitals, and we believe this is an accurate estimation of the true readmission rate after esophagectomy.

This study reveals some further interesting findings with regard to regionalized care. More patients achieved hospital discharge within 10 days at thoracic centers $(39.1 \%$ at thoracic vs $26.3 \%$ at non-thoracic centers), while achieving the same readmission rate. This likely represents the trend toward decreased hospital stays over time but may also be the result of improved multidisciplinary care at regionalized centers, including specialized nursing, dietetics, and physiotherapy care, and protocolled care developed through center expertise. Furthermore, regionalized centers may have greater resources to rescue deteriorating patients. This hypothesis is supported by the increased ICU care we observed at thoracic centers. Although the proportion of patients requiring greater than 7 days of ICU care was similar at thoracic and non-thoracic centers $(19.5 \%$ vs $20.4 \%$, respectively), the proportion of patients requiring between 3 and 7 days of ICU care was $35.7 \%$ in the thoracic center group and $29.3 \%$ in the non-thoracic center group. We also observed that patients at thoracic centers received increased outpatient supports. Although changes in outpatient care were not part of Cancer Care Ontario's regionalization strategy, this may have occurred either through a change in the local delivery of care across Ontario's health administration regions (LHINs), or because of a greater recognition by specialized centers for the need to connect patients with homecare services. This also resulted in a small decrease in the number of patients requiring transfer to a rehabilitation facility after the index surgical admission in the thoracic center group.

Although not the primary objective, our study uncovered 2 important sex differences in patients undergoing esophagectomy. First, female patients were less likely to be treated at a thoracic center. Sex-related disparities in referral for specialist cancer care has been reported in other studies. ${ }^{29-32}$ It is unclear whether this is due to provider bias causing lack of referral or driven by patient choice. For example, among patients randomized to screening for colorectal cancer in the United Kingdom, part of the reason women were less likely to be screened was explained by different attitudes and preferences for care. ${ }^{33}$ Second, female sex was associated with increased risk of readmission, a finding that has been observed in the cardiac literature after myocardial infarction and percutaneous coronary intervention. ${ }^{34,35}$ Possible explanation includes the fact that women are more likely to be the caregiver and less likely to have support at home, thus increasing their chances of presenting to hospital when a concern arises postoperatively. Further examination of factors leading to increased readmission for women is necessary to develop support mechanisms to prevent these visits.

There are limitations to note in this study. The analysis does not include cancer stage. Greater-stage patients are more likely to have greater weight loss at presentation, poor performance status, and experience complications, all of which could increase the risk of readmission. Since greater-stage patients are more likely to be referred to a 
TABLE 4. Multivariable analysis for predictors of 90-day readmission following esophagectomy

\begin{tabular}{|c|c|c|}
\hline Predictor & $\begin{array}{c}\text { Odds ratio } \\
(\mathbf{9 5} \% \text { confidence interval })\end{array}$ & $P$ value \\
\hline Surgery at thoracic center & $1.10(0.95-1.27)$ & .22 \\
\hline $\begin{array}{l}\text { Age, y } \\
18-60 \\
61-70 \\
71+\end{array}$ & $\begin{array}{c}\text { (Ref) } \\
0.89(0.77-1.05) \\
0.81(0.60-1.10)\end{array}$ & .17 \\
\hline $\begin{array}{l}\text { Sex } \\
\qquad \text { Male } \\
\text { Female }\end{array}$ & $\begin{array}{c}(\text { Ref }) \\
1.25(1.12-1.39)\end{array}$ & $<.001$ \\
\hline $\begin{array}{l}\text { Residence status } \\
\text { Urban residence } \\
\text { Rural residence }\end{array}$ & $\begin{array}{c}(\text { Ref }) \\
1.01(0.84-1.21)\end{array}$ & .91 \\
\hline $\begin{array}{l}\text { Income quintile } \\
\quad \text { (Lowest) } 1 \\
2 \\
3 \\
4 \\
\text { (Highest) } 5\end{array}$ & $\begin{array}{c}\text { (Ref) } \\
0.93(0.74-1.16) \\
0.86(0.54-1.36) \\
0.79(0.40-1.58) \\
0.74(0.29-1.84)\end{array}$ & .51 \\
\hline $\begin{array}{l}\text { Comorbidity } \\
\text { Low } \\
\text { Moderate } \\
\text { High }\end{array}$ & $\begin{array}{c}\text { (Ref) } \\
1.51(1.19-1.91) \\
2.28(1.43-3.63)\end{array}$ & $<.001$ \\
\hline $\begin{array}{l}\text { Era of treatment } \\
2002-2008 \\
2009-2014\end{array}$ & $\begin{array}{c}(\text { Ref }) \\
1.03(0.90-1.18)\end{array}$ & .65 \\
\hline
\end{tabular}

thoracic center, not accounting for this may contribute to some residual confounding in the model and explain the lack of difference seen in readmissions at thoracic versus non-thoracic centers. Another consideration is that defining postoperative complications with granularity, in the format suggested by the international Esophageal Complications Consensus Group, is challenging with administrative data studies. ${ }^{36}$ We followed the methodology of other database studies in categorizing complications by system. ${ }^{2,20,37,38}$

In summary, this study found a $27.7 \% 90$-day readmission rate following resection for esophageal cancer. Readmission rates varied significantly even across designated thoracic surgery centers. Surgery at a thoracic center did not reduce the risk of readmission. These results are summarized in Figure 3. Our results suggest that despite universal, regionalized, high-volume esophageal cancer care, there is a minimum readmission threshold following esophagectomy that may be clinically necessary. Further work will need to focus beyond hospital-level changes and include local health system changes to improve out-ofhospital care and reduce preventable readmissions.
90-Day Readmission Following Esophagectomy at Regionalized and Non-Regionalized Centres

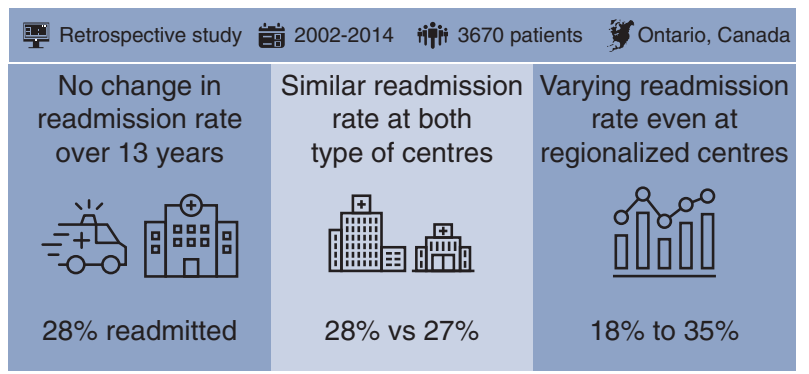

There appears to be a minimum readmission threshold following esophagectomy \& may be clinically necessary

FIGURE 3. Graphical abstract summarizing key study characteristics and results. Ninety-day readmission rates following esophagectomy in Ontario remained relatively stable from 2002 to 2014 , were similar at thoracic and non-thoracic centres, and varied from $18 \%$ to $35 \%$ even at thoracic centers. There appears to be a minimum readmission threshold following esophagectomy and may be clinically necessary.

\section{Conflict of Interest Statement}

Authors have nothing to disclose with regard to commercial support.

\section{References}

1. van Hagen $P$, Hulshof MC, van Lanschot JJ, Steyerberg EW, van Berge Henegouwen MI, Wijnhoven BP, et al. Preoperative chemoradiotherapy for esophageal or junctional cancer. N Engl J Med. 2012;366:2074-84.

2. Bhagat R, Bronsert MR, Juarez-Colunga E, Weyant MJ, Mitchell JD, Glebova NO, et al. Postoperative complications drive unplanned readmissions af ter esophagectomy for cancer. Ann Thorac Surg. 2018;105:1476-82.

3. Hu Y, McMurry TL, Stukenborg GJ, Kozower BD. Readmission predicts 90-day mortality after esophagectomy: analysis of surveillance, epidemiology, and end results registry linked to Medicare outcomes. J Thorac Cardiovasc Surg. 2015 150:1254-60.

4. de Oliveira C, Bremner KE, Pataky R, Gunraj N, Chan K, Peacock S, et al. Understanding the costs of cancer care before and after diagnosis for the 21 most common cancers in Ontario: a population-based descriptive study. CMAJ Open. 2013;1:E1-8.

5. McIlvennan CK, Eapen ZJ, Allen LA. Hospital readmissions reduction program. Circulation. 2015;131:1796-803.

6. Birkmeyer JD, Siewers AE, Finlayson EV, Stukel TA, Lucas FL, Batista I, et al Hospital volume and surgical mortality in the United States. N Engl J Med. 2002 346:1128-37.

7. Birkmeyer JD, Stukel TA, Siewers AE, Goodney PP, Wennberg DE, Lucas FL. Surgeon volume and operative mortality in the United States. $N$ Engl J Med. 2003;349:2117-27.

8. The Expert Panel on Thoracic Surgical Oncology. Thoracic surgical oncology standards. In: Sundaresan S, Haynes AE, reviewers. Toronto (ON): Cancer Care Ontario; September 9, 2005 [Endorsed 2015 March 4]. Program in Evidence-Based Care Practice Guideline Report No.: 17-1 Version 2.

9. Begg CB, Cramer LD, Hoskins WJ, Brennan MF. Impact of hospital volume on operative mortality for major cancer surgery. JAMA. 1998;280:1747-51.

10. Patti MG, Corvera CU, Glasgow RE, Way LW. A hospital's annual rate of esoph agectomy influences the operative mortality rate. J Gastrointest Surg. 1998;2: 186-92.

11. Schlottmann F, Strassle PD, Charles AG, Patti MG. Esophageal cancer surgery: spontaneous centralization in the US contributed to reduce mortality withou causing health disparities. Ann Surg Oncol. 2018;25:1580-7.

12. Fuchs HF, Harnsberger CR, Broderick RC, Chang DC, Sandler BJ, Jacobsen GR, et al. Mortality after esophagectomy is heavily impacted by center volume: retrospective analysis of the nationwide inpatient sample. Surg Endosc. 2017;31: 2491-7. 
13. Wouters MW, Karim-Kos HE, le Cessie S, Wijnhoven BP, Stassen LP, Steup WH, et al. Centralization of esophageal cancer surgery: does it improve clinical outcome? Ann Surg Oncol. 2009;16:1789-98.

14. Robles SC, Marrett LD, Clarke EA, Risch HA. An application of capturerecapture methods to the estimation of completeness of cancer registration. $J$ Clin Epidemiol. 1988;41:495-501.

15. Clarke EA, Marrett LD, Kreiger N. Cancer registration in ontario: a computer approach. In: Jensen OM, Parkin DM, MacLennan R, Muir CS, Skeet RG, eds. Cancer Registration Principles and Methods. Pub No. 95 ed. Lyon, France: IARC; 1991:246-57.

16. Austin PC, van Walraven C, Wodchis WP, Newman A, Anderson GM. Using the Johns Hopkins aggregated diagnosis groups (ADGs) to predict mortality in a general adult population cohort in Ontario, Canada. Med Care. 2011;49: 932-9.

17. Alter DA, Naylor CD, Austin P, Tu JV. Effects of socioeconomic status on access to invasive cardiac procedures and on mortality after acute myocardial infarction. N Engl J Med. 1999;341:1359-67.

18. Krieger N. Overcoming the absence of socioeconomic data in medical records: validation and application of a census-based methodology. Am J Public Health. 1992;82:703-10.

19. Markar SR, Karthikesalingam A, Thrumurthy S, Low DE. Volume-outcome relationship in surgery for esophageal malignancy: systematic review and meta-analysis 2000-2011. J Gastrointest Surg. 2012;16:1055-63.

20. Bendzsak AM, Baxter NN, Darling GE, Austin PC, Urbach DR. Regionalization and outcomes of lung cancer surgery in Ontario, Canada. J Clin Oncol. 2017;35: 2772-80.

21. Goodney PP, Stukel TA, Lucas FL, Finlayson EV, Birkmeyer JD. Hospital volume, length of stay, and readmission rates in high-risk surgery. Ann Surg. 2003;238:161-7.

22. Anderson O, Ni Z, Moller H, Coupland VH, Davies EA, Allum WH, et al. Hospital volume and survival in oesophagectomy and gastrectomy for cancer. Eur J Cancer. 2011;47:2408-14.

23. Bailey SH, Bull DA, Harpole DH, Rentz JJ, Neumayer LA, Pappas TN, et al. Outcomes after esophagectomy: a ten-year prospective cohort. Ann Thorac Surg. 2003; 75:217-22; discussion 22.

24. Lapar DJ, Stukenborg GJ, Lau CL, Jones DR, Kozower BD. Differences in reported esophageal cancer resection outcomes between national clinical and administrative databases. J Thorac Cardiovasc Surg. 2012;144:1152-7.

25. Luketich JD, Pennathur A, Awais O, Levy RM, Keeley S, Shende M, et al. Outcomes after minimally invasive esophagectomy: review of over 1000 patients. Ann Surg. 2012;256:95-103.
26. Mamidanna R, Ni Z, Anderson O, Spiegelhalter SD, Bottle A, Aylin P, et al. Surgeon volume and cancer esophagectomy, gastrectomy, and pancreatectomy: a population-based study in England. Ann Surg. 2016;263:727-32.

27. Borza T, Oreline MK, Skolarus TA, Norton EC, Ryan AM, Ellimoottil C, et al. Association of the hospital readmissions reduction program with surgical readmissions. JAMA Surg. 2018;153:243-50.

28. Ellis RJ, Merkow RP, Bilimoria KY. The hospital readmissions reduction program-targeting weaknesses and finding the readmission floor. JAMA Surg. 2018; $153: 251$.

29. Henning A, Wehrberger M, Madersbacher S, Pycha A, Martini T, Comploj E, et al. Do differences in clinical symptoms and referral patterns contribute to the gender gap in bladder cancer? BJU Int. 2013;112:68-73.

30. Faulds J, McGahan CE, Phang PT, Raval MJ, Brown CJ. Differences between referred and nonreferred patients in cancer research. Can J Surg. 2013;56: E135-41.

31. Etzioni DA, El-Khoueiry AB, Beart RW Jr. Rates and predictors of chemotherapy use for stage III colon cancer: a systematic review. Cancer. 2008;113:3279-89.

32. Bouchardy C, Rapiti E, Blagojevic S, Vlastos AT, Vlastos G. Older female cancer patients: importance, causes, and consequences of undertreatment. J Clin Oncol. 2007; 25:1858-69.

33. Wardle J, Miles A, Atkin W. Gender differences in utilization of colorectal cancer screening. J Med Screen. 2005;12:20-7.

34. O'Brien C, Valsdottir L, Wasfy JH, Strom JB, Secemsky EA, Wang Y, et al. Comparison of 30-day readmission rates after hospitalization for acute myocardial infarction in men versus women. Am J Cardiol. 2017;120:1070-6.

35. Kwok CS, Potts J, Gulati M, Alasnag M, Rashid M, Shoaib A, et al. Effect of gender on unplanned readmissions after percutaneous coronary intervention (from the nationwide readmissions database). Am J Cardiol. 2018;121:810-7.

36. Low DE, Kuppusamy MK, Alderson D, Cecconello I, Chang AC, Darling G, et al. Benchmarking complications associated with esophagectomy. Ann Surg. 2019;269:291-8.

37. Molena D, Mungo B, Stem M, Lidor AO. Incidence and risk factors for respiratory complications in patients undergoing esophagectomy for malignancy: a NSQIP analysis. Semin Thorac Cardiovasc Surg. 2014;26:287-94.

38. Govindarajan A, Urbach DR, Kumar M, Li Q, Murray BJ, Juurlink D, et al. Outcomes of daytime procedures performed by attending surgeons after night work. N Engl J Med. 2015;373:845-53.

Key Words: esophageal cancer, esophagectomy, regionalization, readmission 


\section{APPENDIX E1}

International Classification of Diseases for Oncology, Third Edition (ICD-O-3) topography codes used to define esophageal and gastroesophageal junction cancer: C15.0C15.9, C16.0-C16.2, C16.5, C16.8, and C16.9. Surgical resection was defined using the Canadian Classification of Health Interventions (CCI) codes for esophagectomy or gastrectomy (CCI codes 1.NA.87-92.^ and 1.NF.89-90.^)..$^{37}$

\begin{tabular}{cc}
\hline Adenocarcinoma & Squamous cell carcinoma \\
\hline $81403,81413,81423,81433,81443,81453,82003,82103,82113$, & $80513,80523,80703,80713,80723,80743,80763,80833,85603$, \\
$82143,82503,82553,82603,82613,82623,82633,82903,83103$, & 89803. \\
$83233,83803,84013,84603,84803,84813,84823,84903,85003$, & \\
$85423,85703,85723,85743,85763$. & \\
\hline
\end{tabular}


TABLE E2. Data sources for the study

\begin{tabular}{ll}
\hline \multicolumn{1}{c}{ Database } & Information \\
\hline Ontario Cancer Registry & Cancer information, including histology \\
Ontario Health Insurance Plan Database & $\begin{array}{c}\text { Inpatient and outpatient physician billing data; includes information on diagnoses and } \\
\text { services provided }\end{array}$ \\
$\begin{array}{l}\text { Canadian Institute for Health Information Discharge } \\
\text { Abstract Database (CIHI-DAD) }\end{array}$ & $\begin{array}{c}\text { Information from hospital admissions, including diagnoses and receipt of esophagectomy } \\
\text { or gastrectomy; mandatory reporting system for all institutions in Ontario }\end{array}$ \\
Registered Persons Database (RPDB) & $\begin{array}{c}\text { Derived from all administrative data sources and provides demographic data, vital status, } \\
\text { and details such as date of last contact with the health care system }\end{array}$ \\
2006 Canadian Census & Demographic information including median neighborhood income quintile \\
\hline
\end{tabular}

TABLE E3. Proportion of patients experiencing major postoperative complications, stratified by surgery at a thoracic or non-thoracic center

\begin{tabular}{|c|c|c|c|}
\hline Complication & $\begin{array}{l}\text { Treated at thoracic center } \\
\quad(n=2777,75.7 \%)\end{array}$ & $\begin{array}{l}\text { Treated at non-thoracic center } \\
\qquad(\mathrm{n}=\mathbf{8 9 3}, 24.3 \%)\end{array}$ & $P$ value \\
\hline Cerebrovascular accident, $(\%)$ & $14(0.5)$ & $\leq 5(0.4)$ & .83 \\
\hline Myocardial infarction, $(\%)$ & $57(2.1)$ & $25(2.8)$ & .19 \\
\hline Acute kidney injury, $(\%)$ & $69(2.5)$ & $18(2.0)$ & .42 \\
\hline Respiratory failure, $(\%)$ & $474(17.1)$ & $134(15.0)$ & .15 \\
\hline Pneumonia, (\%) & $117(4.2)$ & $38(4.3)$ & .96 \\
\hline Airway compromise, $(\%)$ & $63(2.3)$ & $7(0.8)$ & .005 \\
\hline Procedure-related, $(\%)$ & $170(6.1)$ & $56(6.3)$ & .87 \\
\hline Pulmonary embolism, (\%) & $15(0.5)$ & $10(1.1)$ & .07 \\
\hline Deep-vein thrombosis, $(\%)$ & $24(0.9)$ & $9(1.0)$ & .69 \\
\hline Cardiac arrest, $(\%)$ & $19(0.7)$ & $11(1.2)$ & .11 \\
\hline Shock, $(\%)$ & $27(1.0)$ & $\leq 5(0.4)$ & .14 \\
\hline Sepsis, $(\%)$ & $47(1.7)$ & $16(1.8)$ & .84 \\
\hline
\end{tabular}

